\title{
El tiempo de la madre o bien sobre el círculo del origen
}

\section{Mother's Time or on the Circle of Origin}

\author{
MARÍA J. BINETTI \\ CONICET \\ Recibido:13-XI-2014 Aceptado definitivamente: 21-XI-2014
}

\section{RESUMEN}

Desde el trasfondo de la cultura, emerge cierto imaginario social que, asentado en la periodicidad biológica de la fecundidad femenina, proyecta a la mujer como un ser cíclico y mudable, por oposición a la linealidad e inmutabilidad masculinas. Este imaginario se remonta a la conciencia humana originaria y prehistórica, para la cual la madre constituía y simbolizaba una realidad cíclica, continuamente renacida de su seno. En el contexto del feminismo de la diferencia, el presente artículo se propone releer en términos metafísicos la simbólica circular y cíclica de la madre, concebida en el origen de la conciencia primitiva, recuperada por la filosofía feminista, y repetida por gran parte del pensamiento moderno y contemporáneo.

\section{PALABRAS CLAVE}

DIFERENCIA SEXUAL-ARQUETIPO-REPETICIÓN-INMANENCIA-DEVENIR.

\begin{abstract}
From the background of culture, it emerges a social imaginary that, settled on the biological basis of female fertility, projects woman as a cyclical and changeable being, as opposed to male linearity and immutability. This imaginary dates back to the original and prehistoric human consciousness, to which the mother constituted and symbolized a cyclical actually, continually reborn from her womb. In the context of Feminism of Difference, this article aims at rereading
\end{abstract}


in metaphysical terms the circular and cyclic symbolic of the mother, conceived at the origin of the primitive consciousness, recovered by Feminist Philosophy, and repeated by a large branch of Modern and Contemporary Thought.

KEYWORDS

SEXUAL DIFFERENCE-ARCHETYPE-REPETITION-IMMANENCE-BECOMING.

\section{INTRODUCCIÓN}

Desde el trasfondo de la cultura, emerge cierto imaginario social que, asentado en la periodicidad biológica de la fecundidad femenina, proyecta a la mujer como un ser cíclico y mudable, por oposición a la linealidad e inmutabilidad masculinas. Este imaginario se remonta a la conciencia humana originaria y prehistórica, para la cual las mujeres no solo constituían ellas mismas una realidad en continua transformación, sino que además simbolizaban un universo cíclico, constantemente renacido de su seno. Los ciclos femeninos representaban entonces la potencialidad de una vida y una naturaleza capaces de sobreponerse a su propio fin por la repetición inagotable de su origen. El círculo, la esfera, la rueda, la luna y la serpiente eran los símbolos de una vida eterna e inagotable, tan circular como la sangre menstrual de la cual nacía.

El hecho de que el imaginario falogocéntrico posterior haya encubierto la continuidad cíclica de lo real bajo la rigidez de una linealidad abstracta, donde principio y fin se excluyen de manera dualista, no hace sino iluminar el sedimento originario de otra concepción metafísica y cultural. Mientras que el sistema patriarcal hegemónico se estableció sobre la claridad y distinción de un origen inmutable y trascendente; la concepción de la humanidad primitiva permaneció en el seno oscuro, ambiguo y contradictorio de una madre en continua muerte y renovación. Respecto del primero, el tiempo es lineal, irrepetible e irreversible. Respecto de la segunda, lo temporal desdobla un origen que se reproduce a sí mismo.

Después de siglos de linealidad falogocéntrica, verticalista e inmutable, lo cierto es que a partir de la muerte del padre y advenimiento de su viernes santo especulativo, el pensamiento filosófico volvió a redescubrir el pulso vital de una realidad en continuo nacimiento. La inmanencia de un origen reproducido y diferenciado en su misma materialidad -a contramano de aquella otra trascendencia inmaterial e infecunda- recuperó a su modo las ideas de creación, circularidad, centro, eterno retorno o devenir absoluto. Lo temporal dejó entonces de excluir de manera dualista a la eternidad, para concebirla en su propio seno e integrarla en cada instante.

Con tal retorno coincide gran parte del pensamiento feminista contemporáneo, concentrado en reconstruir la simbólica de lo femenino en tanto que concepción originaria del ser. Autoras como Luce Irigaray o Luisa Muraro 
- para mencionar solo algunas- comprenden el dinamismo materno como arquetipo metafísico originario y original, no sólo en el sentido cultural de lo prehistórico sino especialmente en el sentido constitutivo de lo humano. Esto supone volver sobre ese imaginario primitivo donde el seno materno era medida y medio de existencia, volver sobre la fantasía de su unidad vital y el deseo de su restitución.

En el contexto de la filosofía feminista y en especial del feminismo de la diferencia, el presente artículo se propone releer en términos metafísicos la simbólica cíclica y circular de la madre, concebida en el origen de la conciencia primitiva, y repetida por gran parte del pensamiento moderno y contemporáneo.

\section{LA PREHISTORIA DE LA MADRE}

La prehistoria de la humanidad comporta una entera constelación simbólica, que muchos autores coinciden en comprender bajo la figura de la Gran Madre, ${ }^{1}$ origen y fundamento de la vida individual, social y universal. El paradigma materno significaba entonces la fuerza creadora y recreadora de la vida, celebrada y bendecida en todas las cosas. Lejos de oponer de manera dualista lo femenino y lo masculino, la madre simbolizaba la vida misma, realizada por igual en toda la naturaleza, sea esta femenina o masculina. Su seno era el seno de la totalidad, el pulso vital, el orden y la medida de lo real. A esto se refiere justamente el sentido etimológico de la madre.

En efecto, las lenguas indoeuropeas concuerdan en remitir el nombre de la madre a la raíz común $m a$, cuya universalidad se extiende hasta nuestros días. ${ }^{2}$ La raíz indoeuropea ma designa no sólo la función generadora y nutricia de la madre, sino que significa también medida, inteligencia y orden, igualmente

1 Cf. R. Briffault, The Mothers. A Study of the Origins of Sentiments and Institutions, 3 vols., London: George Allen, 1927; R. Briffault, The Mothers. The Matriarchal Theory of Social Origins, New York: Howard Fertig, 1993; E. Neumann, The Great Mother, tr. Ralph Manheim, Princeton University Press, 1991; E. Neumann, The Origins and History of Consciousness, 2. vols., New York: Harper \&Brothers, 1962; M. Gimbutas, The Living Goddesses, Berkeley - Los Angeles: University of California Press, 2001; M. Gimbutas, The Goddesses and Gods of Old Europe. $6500-3500$ BC. Myths and Cult Images, Berkeley - Los Angeles: University of California Press, 1996; M. Gimbutas, The Language of the Goddess, Harper \& Row, San Francisco 1989; Joan Marler (ed.), The Civilization of the Goddess, New York: HarperCollins Publishers, 1991.

2 Cf. P. Chantraine, Dictionnaire Étymologique de la Langue Grecque, Paris: Éditions Klincksieck, 1974, vol III; E. Ross Wharton, Etymological Lexicon of Classical Greek. Etyma Graeca, Chicago: Ares Publishers, 1974; A. Ernout - A. Meillet, Dictionnaire Étymologique de la Langue Latina. Histoire des Mots, Paris: Librairie C. Klincksieck, 1939; B. G. Walker, The Woman's Encyclopedia of Myths and Secrets, New York: Harper Collins Publishers, 1983. 
determinantes de la función materna. Por ejemplo, en sánscrito, madre se dice matar y designa tanto a quien genera la vida como a quien mide y conoce lo generado. De allí viene matra: útero y medida; matih: medida y conocimiento exacto; mimati: medir. Matemática significa, por derivación, el conocimiento o la sabiduría de la madre. La convertibilidad del término madre con la medida y el conocimiento es también identificable en la palabra babilónica me: sabiduría materna, y reaparece en el sánscrito medha: sabiduría femenina. El vocablo griego $\mu$ ๆ́ $ๆ \rho$ : madre procede del sánscrito y significa por extensión la tierra o, poéticamente, lo que está en el origen de todo. De $\mu \eta ́ \tau \eta \rho$ viene $\mu \eta ́ \tau \rho \alpha$ : matriz, útero y también medida, sustancia, esencia, núcleo. Por implicación, $\mu \eta ́ \tau \rho \alpha$ significa sabiduría y prudencia. Con ella se relaciona $\mu \varepsilon ́ \tau \rho o v: ~ m e d i d a$, de donde surgen muchos otros términos de cálculo. En cuanto al latín, de la $\mu \eta ́ \tau \eta \rho$ griega procede la mater-matris: quien nutre al niño, mientras que de $\mu \eta ์ \tau \rho \alpha$ derivan menstrua: menstruación; menstrualis: que es tanto menstrual como mensual; mensis: mes, en referencia a la medida menstrual; metior: medir; mensus o mensura: medida y mens: mente. Por lo tanto, también el latín asume la matrix materna como medida espacio-temporal

Dicho brevemente, la etimología indoeuropea manifiesta la intuición del seno materno como medida, conocimiento y sabiduría, ante todo, del hombre concreto individual y, por extensión analógica, del universo entero. Esto es consistente con un estadio cultural primitivo, donde la función materna era concebida como fundamento de lo real, cuya vitalidad irradiaba en todas las cosas. Ahora bien, lo que nos interesa destacar aquí es precisamente que la medida representada por la madre reproduce en cada cosa el dinamismo cíclico de su sangre menstrual, origen y alimento de todo, y de aquí la naturaleza circular, del ser tal como es concebido por la conciencia originaria.

Sobre la percepción de la conciencia primitiva, se sostiene la idea de que la sangre menstrual creaba, formaba y alimentaba el nuevo ser gestado, combinando y midiendo los elementos de ese caos acuoso de su seno. De aquí que la sangre fuera interpretada desde tiempos inmemoriales como el principio vital, el alma, la sustancia de lo humano, ${ }^{3}$ a cuyo arquetipo remitía el misterio del cambio y la transformación. ${ }^{4}$ A la energía creadora de la menstruación se deben tanto el carácter sagrado, mágico y numinoso atribuido a la sangre, como los primeros tabúes reconocidos por la humanidad. Su naturaleza originaria no actuaba como una medida extrínseca y cuantitativa, sino como la forma inmanente y cualitativa de lo producido, razón por la cual la realidad

3 Cf. R. Briffault, The Mothers. A Study of the Origins..., cit., vol. 2, pp. 412 - 416; cf. también. G. Walker, The Woman's Encyclopedia ..., cit., pp. 635 ss.

4 Cf. E. Neumann, The Great Mother..., cit., p. 31. 
entera asumía el dinamismo cíclico de su origen, el continuo fluir y refluir de su medida menstrual.

Desde el punto de vista macrocósmico, la periodicidad menstrual coincide con las fases de la luna, interpretada por la conciencia primitiva como la causa última de la fertilidad y la concepción universal, madre por eso de la humanidad. ${ }^{5}$ La luna representaba la fuerza auto-reproductora de lo real, que el primitivo asumió como «la única medida de tiempo», ${ }^{6}$ no en un mero sentido extrínseco y abstracto, sino como la energía misma del devenir y la duración. Los calendarios menstruales-lunares ofrecieron la primera medición de una realidad cíclica, capaz de convertir su propio fin en un nuevo comienzo. A semejanza de la luna, la capacidad autorregeneradora de la serpiente la convirtió en el animal menstrual y lunar por antonomasia, símbolo de una eternidad cíclica en continua renovación. ${ }^{7}$

Al ritmo circular de su origen, el universo entero amanece y declina; nace, muere y vuelve a surgir. Esto vale análogamente para la vida vegetal, animal, humana y cósmica, que no son sino diversos aspectos de un mismo organismo, sujeto a destrucciones y reconstrucciones periódicas. Entre la vida y la muerte, el ser y el no ser, lo que media es la restitución del origen como instancia generadora y superadora de la oposición; entre lo uno y lo otro, media lo tercero de un efectivo regressus ad uterum, principio y medida de toda transformación.

El significante originario de esta realidad cíclica y en constante creación es, según lo dicho, la Gran Madre. En términos metafísicos, su seno representa un monismo dinámico, actualizado por el continuo fluir y refluir inmanente de su sangre vital. La madre-matriz expresa la esencia de una realidad autorreproducida, afirmada en la inmanencia de su origen. Ella expresa por lo mismo una esencia atravesada por la diferencia de su propia reproducción, en la cual se reconoce como energía creadora. Los atributos simbólicos que la conciencia primitiva le asigna a la madre son consistentes con esa contradicción esencial, que desdobla y diferencia la unidad de origen, a la vez que habilita su continua regeneración.

Por una parte, la Gran Madre es la contradicción misma de todos los opuestos que la realidad expresa. Su arquetipo contiene siempre las dos partes del todo, su cara y contracara: seno fecundo, nutricio y benefactor, así como también seno terrible, hambriento y devorador; lugar de nacimiento y tumba de la muerte; principio luminoso y oscuro, divino y bestial; virgen y madre; inmemorialmente vieja y eternamente joven. Sus símbolos pueden ser también dobles: la doble hacha, la doble espiral, la rueda que hila hacia la derecha y

5 Cf. R. Briffault, The Mothers. The Matriarchal Theory ..., cit., p. 288.

6 R. Briffault, The Mothers. A Study of the Origins..., cit., vol. 2, vol. 2, p. 600.

7 Cf. E. Neumann, The Great Mother..., cit., p. 18. 
la izquierda, los ciclos lunares de crecimiento y disminución, la puerta de entrada y de salida, el árbol cuyas raíces se hunden en la tierra y cuyas ramas se alzan al cielo, etc. ${ }^{8}$ La Madre genera y destruye y, más aun, ella misma nace, muere y se transforma. De aquí que, siguiendo a Marija Gimbutas, entre sus epifanías figuren la mariposa, la oruga o crisálida, símbolos todos de una vida en continua renovación. ${ }^{9}$

Sin embargo, por la otra parte, su seno omninclusivo supera la contradicción sida en y por la unidad dinámica y amónica que ella presupone y produce. $\mathrm{Su}$ arquetipo es tanto la contradicción como el centro, el entre, lo tercero de una mediación superadora, que restituye la integridad del origen. Se trata por eso de una dualidad o diferencia no dualista, vale decir, de una identidad original diferenciada y dialéctica, cuyo devenir produce y salva la contradicción. En otras palabras, entre la vida y la muerte, el origen y el fin, la oscuridad y la luz, etc. media un principio de unidad, intercambio y transformación, justificado por la naturaleza uróbica del seno materno. Este tercer término medio representa el centro de una circunferencia infinita, replicado en cualquier punto de la misma. Todo nace y vuelve a él, siempre el mismo mundo y la misma historia, sin embargo ni tan idénticos para excluir su retorno, ni tan diferentes para ocultar la identidad de su origen.

La medida de la madre no es ni pura unidad ni pura contradicción, sino ambas cosas a la vez en el medio de un devenir que convierte cada punto de llegada en un nuevo comienzo. Esto supone una concepción triádica de la medida matricial, que la conciencia primitiva supo hipostasiar en la figura de tres divinidades diferentes. ${ }^{10}$ En rigor, la Gran Madre no es ni una ni dos, sino tres: lo tercero superador de su propia diferencia, el medio que conserva la ambivalencia del todo y actúa como sustrato elemental de transformaciones. De aquí que el origen permanezca como centro de todas las diferencias posibles, como unidad multiplicada y repetida en cada parte. Por la triplicidad, el devenir garantiza la identidad de su origen, mientras que el origen asegura su continua reproducción

En medio de todas las diferencias que la realidad despliega, el seno materno representa ese núcleo de permanentes transformaciones. Asimilado a una caverna, vasija o caldera, aquel se ofrece como instancia de transición en el pasaje de una cosa a la otra. Erich Neumann comenta al respecto que, para el primitivo, «la transformación es posible solo cuando lo que se debe

8 M. Sjöö - B. Mor, The Great Cosmic Mother: Rediscovering the Religion of the Earth, New York: Harper Collins Publishers, 1991, p. 174.

9 Cf. M. Gimbutas, The Goddesses and Gods of Old Europe..., cit., pp. 196, 237.

10 Cf. R. Briffault, The Mothers. A Study of the Origins..., cit., vol. 2, vol. 3, p. 159; también M. Sjöö - B. Mor, The Great Cosmic Mother..., cit., pp. 147, 407. 
transformar ingresa en el principio femenino; es decir, muere retornando a la vasija-madre, sea esta la tierra, el agua, el mundo subterráneo, una urna, cofre, caverna, montaña o caldera mágica»». ${ }^{11}$ Todo cambio, incluida la muerte, pertenece al seno de la vida y a su energía creadora, y de aquí la exigencia de su mediación permanente. A esta intuición originaria responde la simbólica ritual del regressus ad uterum descrita por Mircea Eliade, la cual no constituye para la mente primitiva un mero formalismo vacío sino un estricto y efectivo «retorno al origen ${ }^{12}$ como condición de posibilidad de todo cambio.

Pero el retorno al origen es estrictamente hablando el retorno del origen mismo: su reproducción o repetición y, por lo tanto, la creación de una nueva vida. A esto se refiere Eliade cuando habla del arquetipo materno como de un «comienzo absoluto», ${ }^{13}$ vale decir, de un origen repetido y continuado en todos los comienzo del tiempo. El origen vuelve siempre mediante su propia reproducción, porque no se trata aquí de un principio puro y trascendente, sino de una materialidad desdoblada en su obra, capaz de concebir y contener el mundo entero. El devenir universal resulta así la absoluta reafirmación de este origen, tan eterno como los ciclos menstruales de la luna, las cosechas, las estaciones y los días.

La concepción circular del devenir no solo salva las apariencias del mundo empírico - ese eterno retorno de lo mismo-, sino que expresa además un monismo ontológico, vitalista y orgánico, según el cual lo uno nace, muerte y se transforma en todas las cosas. Unidad dialéctica del origen y circularidad del tiempo y el devenir constituyen una misma intuición de la conciencia primitiva, medida y resuelta por la partición inmanente del seno materno. Que la realidad sea un círculo significa el origen concibe lo otro por la reproducción de sí mismo, que lo creado no surge ex nihilo sino que nace ex matre, y que lo hace a cada instante de su regressus ad uterum.

Marija Gimbutas comenta al respecto que, mientras que la cultura patriarcal indoeuropea introdujo la concepción lineal del tiempo, dominada por la exclusión dualista del principio y el fin, y resuelta por la muerte como fin definitivo de la vida, en cambio la cultura matricial de la Europa prehistórica estuvo dominada por «la rueda de la vida y su retorno cíclico». ${ }^{14}$ Allí la muerte pertenecía a la vida, la vida pertenecía al origen y el origen, a su propia reproducción. Allí el tiempo era reversible, lo sido era lo actual y el futuro, repetición.

Tal es la medida absoluta concebida por la conciencia primera y fundacional de lo humano bajo el arquetipo del seno materno.

11 E. Neumann, The Great Mother..., cit., p. 292.

12 M. Eliade, Mith and reality, tr. W. R. Trask, New York: Harper, 1975, p. 52.

13 Ibid.. p. 88.

14 M. Gimbutas, The Living Goddesses..., cit., p. 4. 


\section{LA EXPERIENCIA PREHISTÓRICA DE LA MADRE}

La prehistoria de la conciencia humana se dice tanto en sentido cultural cuanto en sentido subjetivo, ambos simbólicamente consistentes con una matricialidad dinámica y circular. Si desde el punto de vista cultural, la inmanencia reproductora del seno materno se proyectó como significante universal de una vitalidad cíclica; desde el punto de vista subjetivo, la experiencia arquetípica de la relación materna constituye el fundamento repetido de la vida psíquica individual. En los dos casos, la inmediatez del origen materno queda mediada por la actualidad de su desdoblamiento diferencial. En lo que sigue, atenderemos al modo en el cual ciertas lecturas sicoanalíticas interpretan el arquetipo materno, teniendo como referencia última la angustia primordial del nacimiento abordada por Inhibición, sintoma y angustia..$^{15}$

El sicoanálisis de orientación jungiana ha incorporado la simbólica histórico-universal del seno materno a la experiencia subjetiva de la Gran Madre en tanto que arquetipo colectivo, tan arcaico como actual y vivo. Por arquetipo, entiende Carl Jung un impulso o tendencia síquica inconsciente, que precede la conciencia individual y hace posible todas sus representaciones y acciones. ${ }^{16}$ Por arquetipo materno, él entiende el impulso más profundo y elemental de la subjetividad, su fuerza una e idéntica, previa al parto de la individualidad y la discriminación consciente de las formas, y por lo tanto más íntima al yo individual que este a sí mismo. El arquetipo materno designa el origen uno e indeterminado del yo, en el cual todo está entremezclado, indiferenciado y en flujo. ${ }^{17}$ El actúa como sustrato de la partición individual, tanto en el movimiento generador de lo particular como en el proceso de su disolución, vale decir, tanto en su nacimiento como en su retorno ad uterum. Una misma energía síquica determina así el principio y el fin, el origen y la muerte, por una suerte de identificación dialéctica y circular. Erich Neumann comenta al respecto que «el carácter elemental de lo femenino tiende a disolver el ego y la conciencia», ${ }^{18}$ disolución que expresa la «tendencia del yo a retornar a su

15 Cf. S. Freud, Inhibición, síntoma y angustia, en Obras Completas, Buenos Aires: Amorrortu, 1980, vol. XX, pp. 73-164.

16 Cf. C. Jung, El hombre y sus símbolos, tr. L. Escolar Bareño, Barcelona: Caralt, 1984, p. 95; C. Jung, Psicología y religión, tr. Ilse T. M. de Brugger, Buenos Aires: Paidós, 1961, p. 21; E. Neumann, The Great Mother..., cit.

17 E. Neumann, The Origins and History of Consciousness ..., cit., vol. 2, p. 323; también C. Jung, El hombre y sus simbolos..., cit., pp. 222-23.

18 E. Neumann, The Great Mother..., cit., p. 33. 
estado de inconsciencia originaria»». ${ }^{19}$ Esto significa que, desde el punto de vista jungiano, la energía matricial constituye un núcleo de indeterminación originaria continuamente activo en la reproducción del ego y en la cual coexiste la fuerza dialéctica de la contradicción. De aquí la constante tensión que el yo experimenta entre el inconsciente colectivo -el todo- y la conciencia individual, entre su nacimiento y su muerte, entre su salida ex utero y su regreso ad uterum, ambos recíprocamente relacionados en la unidad inmanente de su seno y continuamente actualizados en la reproducción del origen matricial.

La circularidad del paradigma materno reaparece a su modo en el sicoanálisis de Melanie Klein, ${ }^{20}$ para quien la relación originaria con el pecho materno se recupera y repite en toda relación ulterior. Según Klein, el pecho materno constituye el objeto inmediato de deseo, la primera relación objetal, percibida como fuente de vida y alimento tras la pérdida de la unidad intrauterina. La simbiosis con el pecho materno repite y restaura sui generis la fusión intrauterina, a la vez que ella misma es restaurada y repetida por toda otra relación conforme sea el nivel de satisfacción producido por su experiencia primaria. En efecto, cuando el pecho materno resulta satisfactorio - el pecho bueno- la madre es interiorizada por la subjetividad como energía gratificante y creadora; de lo contrario, el pecho malo es subjetivado como energía envidiosa y destructiva. En ambos casos, la madre funciona como fuerza arquetípica, ambigua y contradictoria, capaz tanto de crear como de destruir. Su identificación se proyecta a toda otra experiencia, el gozo de su pecho se repite en cualquier otro gozo, y su unidad relacional hace posible toda otra unidad.

Desde el punto de vista kleiniano, el pasaje del seno al pecho materno, así como desde este último a cualquier otro objeto, se produce por una suerte de pérdida y restitución superadora, de ruptura y conservación, que expresa no solo la dialéctica y circularidad de la relación materna, sino además su continua actualidad dinámica, al modo de un centro o medio multiplicado en todas partes. Con tal circularidad coincide Julia Kristeva, para quien la madre es continuamente reencontrada, recomenzada o recreada mediante la misma libertad que nos separa de ella. ${ }^{21}$ Tanto Klein como Kristeva conciben el origen materno como una continua repetición -subjetiva e inconsciente- promovida por «la esperanza, dice Kristeva, de volver a encontrar la comprensión total reunificando las partes escindidas e incomprendidas del yo»». ${ }^{22}$ En una palabra,

19 Ibid., p. 26.

20 Cf. M. Klein, Envidia y gratitud, en Obras completas, vol. 3, Buenos Aires: Paidós, 1980.

21 J. Kristeva, El genio femenino. La vida, la locura, las palabras. 2. Melanie Klein, Madrid: Paidós, 2001, pp. 120-22.

22 Ibid., p. 103. 
la pérdida de la madre, su deseo y repetición son, síquicamente entendidas, una misma acción restituyente.

En el mismo sentido transita el psicoanálisis lacaniano, según el cual la relación materna determina un origen inmediatamente perdido y mediatamente repetido. Para Lacan, ${ }^{23}$ el cuerpo de la madre constituye la primitividad de un goce que el inconsciente comprende como lo auténticamente real, anterior a las mediaciones simbólicas del lenguaje. No obstante, se trata aquí de una realidad subjetivamente establecida a la manera arquetípica de lo ya sido y perdido, de cuya falta emerge el deseo como rememoración de lo real. La relación materna resulta entonces la causa última del deseo, no solo como su objeto sino además como sujeto del mismo, ${ }^{24}$ según la circularidad perfecta de un acto que involucra, en definitiva, la alteridad originaria.

La circularidad del origen materno retorna como sujeto y objeto último de un deseo cuya realización es esencialmente un reencuentro. En este sentido, comenta Colette Soler, puede decirse que «el primer amor es siempre el segundo»,${ }^{25}$ toda vez que lo segundo no es sino el continuo intento por restituir lo esencialmente sido. La madre arquetípica es la madre perdida y deseada, y por eso la prehistoria de su relación subjetiva pertenece al presente de su dinamismo esencial, vale decir, a un esencial regressus ad uterum. Aquellos 9 meses de habitación intrauterina, restituidos por la continuidad del pecho materno y repetidos por su palabra creadora, determinan la posibilidad deseante de la subjetividad, como si el deseo - que desde $\mathrm{Hegel}^{26}$ a Lacan ha sido el deseo del/a otro/a - no fuera sino el deseo de esa unidad originaria, tan objetiva como subjetiva, tan idéntica como otra.

En tal contexto sicoanalítico, especialmente lacaniano, emerge el feminismo de la diferencia de Luce Irigaray, concebido en torno al «círculo de la madre» ${ }^{27} \mathrm{y}$ articulado por su deseo, ese deseo que el falogocentrismo convirtió en el continente prohibido de la subjetividad. Irigaray comprende lo materno como «la relación a la vez más arcaica y más actual». ${ }^{28}$ Tan arcaica como el

23 Cf. J. Lacan, Seminario XX: Aun, ed. J. A. Miller, Buenos Aires: Paidós, 1992, p. 339.

24 Cf. B. Baas, Le désir pur. Parcours philosophiques dans les parages de J. Lacan, Louvain: Peeters, 1992, pp. 49-50.

25 C. Soler, Lo que Lacan dijo de las mujeres. Estudio de psicoanálisis, Buenos Aires: Paidós, 2010, p. 301.

26 Cf. G.W. F. Hegel, Fenomenología del espiritu, tr.. W. Roces, México: Fondo de Cultura Económica, 1966, pp. 111 ss.

27 L. Irigaray, Speculum of the other Woman, tr. G. C. Gill, New York: Cornell University Press, 1985, p. 166

28 L. Irigaray, Le corps-à-corps avec la mere, Montréal : Les editions de la pleine lune, 1981, p. 29 ; cf. también M. Boulous Walker, Philosophy and the Maternal Body. Reading Silence, 
cuerpo a cuerpo de un goce real e inmediato, previo a toda simbolización, y tan actual como la repetición del deseo, la angustia, la locura.

La pérdida de la unidad matricial -su parto-retorna como deseo y cuando el deseo ha perdido su objeto, entonces juega. Según Irigaray, el juego está en el trasfondo de un reencuentro que se revela, en última instancia, imposible, y que ella lee en el caso freudiano del fort-da: ese juego que restituye la presencia perdida de la madre. ${ }^{29}$ Porque el origen es lo sido, entonces es posible desear y jugar su retorno, un retorno que significa para Irigaray restituir el misterio creador de la materia, la sacralidad de la sangre humana y la fluidez transformadora de su energía, tal como supieron serlo en el pasado de la conciencia primitiva, antes del matricidio falogocéntrico.

En continuidad con el pensamiento de Irigaray, Luisa Muraro entiende que «el principio materno es, en rigor, prehistórico», ${ }^{30}$ preverbal y prerrepresentativo, y su originalidad actúa como el ancla de indefinidas sustituciones. Esto significa que la relación primordial con la matriz de la vida habilita cualquier otra relación, por la sustitución y restitución simbólica de su inmediatez, ${ }^{31}$ vale decir, por su propia mediación o repetición diferenciante. Lo que Muraro denomina «mediación» constituye realmente un dinamismo circular, capaz de restituir la unidad perdida del origen por la sustitución de algo otro, que repite y retoma el lugar de lo originario. En sus propias palabras, «la mediación verdadera pone en círculo la sustitución de la madre con su restitución», ${ }^{32}$ de donde nace todo el universo simbólico de la subjetividad individual, creadora además por su palabra. En estos términos, Muraro concibe lo real como mediación de la inmediatez materna, en y por la sustitución/restitución de su unidad vital.

Hasta aquí, podríamos decir que, así como la cultura prehistórica da testimonio de un Gran Madre cíclica, atravesada por todas las diferencias posibles, reproducida en cada cosa y transfigurada por su continuo devenir, así mismo el inconsciente subjetivo comprende el arquetipo materno como un origen desgarrado por su pérdida y restituido por la actualidad continua de la existencia. Tanto en su dimensión cultural como subjetiva, la reproducción, el parto, la partición de la matriz materna suponen una diferencia que, sin abandonar la inmanencia del origen, genera su constante reafirmación: ese círculo en el cual el ex y el ad útero se invierten recíprocamente.

London: Routledge, 1998, p. 163.

29 Cf. L. Irigaray, en John D. Caputo (ed.), The Religious, Malden-Oxford: Blackwell, 2002, p. 113.

30 L. Muraro, «La verdad de las mujeres», en Duoda. Estudis de la Diferència Sexual, 38 (2010), pp. 71-126, p. 121.

31 Cf. L. Muraro, El orden simbólico de la madre, tr. B. Albertini, Madris: horas y Horas, 1994, pp. 56-58, 80.

32 Ibid., p. 82. 
La inmediatez indeterminada y una del origen materno nunca es tal, sino en y por la oposición que lo escinde y tensiona, esto es, por esa mediación que lo convierte en un origen ya perdido, pasado, sido, no menos que deseado, restituido y actual. Este es uno de los sentidos en los que puede leerse a Alison Stone, cuando asegura que «recordar el pasado materno es integral a la maternidad», ${ }^{33}$ un pasado de cuya inmediatez solo quedan la diferencia y el anhelo. La pérdida es intrínseca y esencial a la relación materna, porque esta supone tanto la unidad matricial como su parto y separación, ambos tensionados dialécticamente por una misma energía circular que nace y vuelve al origen. De aquí la contemporaneidad de aquel pasado inmemorial, capaz de desatar el presente y el futuro.

La partición que el seno materno representa, no tiene nada que ver con la separación dualista y trascendente que caracteriza a la ideología falogocéntrica -donde el hijo siempre es extraño al cuerpo del padre-sino más bien con una diferencia concebida y contenida en la inmanencia del origen matricial. ${ }^{34} \mathrm{La}$ madre diferencia y separa no al modo de una exclusión irreductible, sino a la manera de un centro o medio de inclusión, capaz de mediar la oposición en la pura reciprocidad de su unidad vital. De allí la continuidad y proximidad que el arquetipo materno supone, cuyo seno determina no la relación -sustancialentre dos cosas, sino la relación del origen con su propia reproducción, de la cual resulta el tres de lo recíproco y circular.

Que la madre determine y exprese una relación triangular es, además de la intuición de la conciencia primitiva, un presupuesto del feminismo contemporáneo. En la triangulación de lo materno, la relación misma constituye lo tercero, el medio o centro que habilita tanto la diferencia cuanto la continuidad y reciprocidad del vínculo. ${ }^{35}$ Lo mismo vale para el carácter dinámico del cuerpo materno, que la mente primitiva intuye como caverna de secretas transformaciones, mientras que el feminismo contemporáneo propone como modelo de una metafísica sostenida en la fluidez, indecidibilidad y contradicción.

Lo que arcaicamente representaba la figura triangular del seno materno, vuelve a la conciencia feminista contemporánea como una «metafísica de la inmanencia» $\mathrm{y}$ «del devenir» ${ }^{36}$ atravesada por la diferencia absoluta del/a hijo/a y restituida en su desdoblamiento esencial. Primitividad y contemporaneidad coinciden así en la matricialidad de un origen, capaz de reproducirse a sí mismo.

33 A. Stone, Feminism, Psychoanalysis, and Maternal Subjectivity, London-New York: Routledge, 2012, p. 148.

34 Ibid., pp. 162-63.

35 Ibid., p. 63; cf. también J. Benjamin, The Bonds of Love. Psychoanalysis, Feminism, and the Problem of Domination, New York: Pantheon Books, 1988.

36 C. Battersby, Phenomenal Woman, New York: Routledge, 1998, p. 11; cf. también M. Boulous Walker, Philosophy and the Maternal Body..., cit. 


\section{A MODO DE CONCLUSIÓN: \\ UN ORIGEN QUE RETORNA AL PENSAMIENTO CONTEMPORÁNEO}

Si bien no en el nombre de la madre, sí al menos en el de un padre agónico en un templo desierto durante ese viernes santo especulativo, lo cierto es que a partir de la modernidad romántica e idealista, el dualismo de aquel origen inmaterial y trascendente, consistente con la eternidad abstracta de un tiempo lineal e irreversible, fue cediendo su hegemonía a un monismo dinámico, consistente con el desdoblamiento dialéctico del origen y afirmado en la eterna circularidad de un presente absoluto. Por lo menos a partir de la modernidad, la inmanencia del origen -en lugar de aquel falogocéntrico fundamento, inmutable y remoto- sentó las bases especulativas para una refundación de lo real, no en el más allá de una perfección inmaterial, sino en el más acá de su seno diferido y desgarrado.

Según nuestra lectura, el giro metafísico del idealismo romántico se produjo en el sentido de un retorno a la conciencia primitiva y elemental, gestada en la oscuridad intrauterina de la madre y nacida de su propia diferencia esencial. De aquí la resignificación de categorías tales como la noche, lo abismal, la contradicción, el centro, el medio o círculo del devenir, antes excluidas de lo absoluto y ahora incluidas en su Bildung concreta y singular. Así por ejemplo, el romanticismo temprano del Atheneum (Jena, 1798-1800) ${ }^{37}$ no solo rehabilita la oscuridad de la noche infinita y la negatividad de la muerte como instancias transicionales en el devenir creador de la vida, sino que presupone con ello la circularidad de un absoluto, que atraviesa su propia muerte y negación a fin de recrearse. A imagen y semejanza de esa Gran Madre renacida de su seno, el absoluto idealista conoce la noche de su propia contradicción, que es tanto tumba como seno y caldera de transformación.

La concepción enciclopédica -circular- de la realidad y el conocimiento asumida por los primeros románticos, es sistematizada por Hegel $^{38}$ a través de la dialéctica del concepto, que en definitiva no expresa sino la reproducción de lo otro en el seno de lo uno. A tal movimiento inmanente obedece la concepción hegeliana de la esencia - gewesen ${ }^{39}$ entendida como lo sido, la memoria del

37 Cf. Novalis, Himnos a la noche. Cantos espirituales. Otros poemas, tr. M. de Montoliu, Buenos Aires: Ediciones del Mediodía, 1971; Novalis, Los fragmentos. Los discipulos en Sais, tr. M. Maeterlinck, Buenos Aires: El Ateneo, 1948; F. Schelegel, Fragmentos, tr. E. Uranga, México: Universidad Nacional Autónoma de México, 1958; F. Schlegel, Dialogue on Poetry and Literary Aphorism, tr. E. Behler - Roman Struc, The Pennsylvania State University Press, 1968. Press, 1986.

38 Cf. T. Rockmore, Hegel's Circular Epistemology, Bloomington: Indiana University

39 Cf. G. W. F. Hegel, Ciencia de la Lógica, trad. A. y R. Mondolfo, Buenos Aires: Solar 
ser, su pasado, conforme con la circularidad de un devenir cuya actualidad repite lo originario. A la sazón, Catherine Malabou ${ }^{40}$ comenta que la esencia no es para Hegel la medida fija, clara y distinta del ser, sino su energía transformadora y, por lo mismo, una determinación contradictoria y negativa. La esencia es la negación por la cual el ser se desdobla, contradice y transforma, a imagen de aquella oscura caverna de profundas transformaciones. Si en los sistemas falogocéntricos, la esencia trasciende y precede eternamente al ser, la esencia romántico-hegeliana «procede del ser; por consiguiente, no existe inmediatamente, sino que es un resultado de aquel movimiento», ${ }^{41}$ vale decir, resultado de ese círculo que retorna a lo sido.

Desde el punto de vista temporal, la inmanencia circular del origen supone la absolutidad del tiempo, de manera tal que cada uno de sus instantes repite lo originario en el aquí y el ahora del devenir. Cada instante del tiempo es el «allí» ${ }^{42}$ de lo absoluto, su repetición diferida, el círculo de un origen que siempre vuelve a comenzar. Autores como Kierkegaard o Derrida, para mencionar sólo algunos, recogen esta transvaloración absoluta del tiempo, devenido el sujeto de una eterna repetición. El instante kierkegaardiano, por su parte, asume el peso de lo eterno para convertirse en el tiempo mismo del origen. En tanto que «átomo de la eternidad», ${ }^{43} \mathrm{el}$ instante determina ese centro que media lo pasado y lo futuro, la temporalidad y lo absoluto, el todo y la parte. Tal es asimismo el sentido de lo que algunos otros autores llaman aiôn $n^{44}$ y entienden como esa eternidad originaria, atravesada por la procesualidad indetenible del tiempo.

De instante en instante, lo que acontece no es la mera sucesión de finitudes sino la repetición de una eternidad originaria. El instante es el tiempo de la repetición, en la cual el origen se desdobla y reproduce temporalmente, y de aquí su vínculo con la diferencia de un pasado ya partido y perdido. De uno u otro modo, autores como Nietzsche o Kierkegaard, Deleuze o Derrida relacionan la repetición con la afirmación pura y creadora de la diferencia ${ }^{45}$, vale decir, con

- Hachette, 1968, pp. 343 ss.; también G. W. F. Hegel, Enciclopedia de las ciencias filosóficas en compendio: para uso de sus clases, trad. R. Valls Plana, Madrid: Alianza, 2005, §112.

40 Cf. C. Malabou, Changing Difference. The Feminine and the Question of Philosophy, tr. C. Shread, Cambridge-Maden: Polity, 2011, p. 136.

41 G. W. F. Hegel, Ciencia de la Lógica ...cit., p. 343.

42 Cf. G. W. F. Hegel, Fenomenología...cit., p. 468.

43 S. Kierkegaard, Søren Kierkegaards Samlede Varker, ed. A. B. Drachmann, J. L. Heiberg, H. O. Lange, A. Ibsen, J. Himmelstrup, 2ª ed., 15 vol., København: Gyldendal, 1920-1936, IV 395.

44 G. Deleuze: Logique du Sens, Paris: Les Éditions de Minuit, 1969, pp. 192-193; M. Blanchot, Le Pas Au-Delà, Paris : Gallimard, Paris 1973, pp. 21 ss.; J. Derrida, Donner Le temps. 1. La fausse monnaie, Paris: Galilée, 1991, p. 21.

45 Cf. G. Deleuze, Nietzsche \& Philosophy, tr. H. Tomlinson, New York: Columbia 
la inmanencia de un origen que se desgarra a sí mismo a fin de reproducir lo real. Instante y repetición cualifican un tiempo absoluto, circular y reversible, capaz de transformar la unidad del origen en la alteridad de lo creado.

La repetición realiza el poder de la esencia, no como principio falogocéntrico inmutable y trascedente, sino como negación autoactiva en el seno de una vitalidad infinita. Cuando Kierkegaard compara la omnipresencia de la repetición con la esencia en tanto que «das - was - war - seyn», ${ }^{46}$ significa con ello la actualidad de un movimiento negativo, capaz de diferir la inmediatez del origen a la segunda inmediatez de una realidad reduplicada, reproducida, $\mathrm{o}$ bien, mediada por su propia diferencia. En el seno de esta repetición esencial y originaria, identidad y diferencia no se oponen y excluyen de manera dualista sino que se incluyen recíproca y circularmente en la triangularidad de ese medio o centro replicado en todas las cosas. Derrida asegura en este sentido que el «tres es la primera cifra de la repetición», la cifra de una infinitud «de esencia ternaria». ${ }^{47}$ Donde hay tres, hay diferencia y mediación de la diferencia, contradicción y superación de lo contradicho. Tal es el movimiento de la repetición: el de un origen partido y perdido en aquello mismo que lo reproduce.

En conclusión, lo que queremos mostrar o al menos señalar aquí es que, por lo menos a partir de la modernidad romántica e idealista, el pensamiento filosófico parecería reorientado por una intuición primitiva, que no se reduce al mero deceso y descenso de la trascendencia falogocéntrica, sino que arraiga en una fuerza mucho más profunda y elemental, a saber, en la energía creadora del arquetipo materno. $\mathrm{Si}$, como lo postula la repetición kierkegaadiana, para empezar a vivir hace falta estar de vuelta, ${ }^{48}$ el pensamiento contemporáneo habría alcanzado ese punto de inflexión, donde la linealidad se hace punto y el punto retorna al origen.

En ese origen, es la reproducción del seno materno, su desdoblamiento creador, el parto de su unidad, no en el dos de una linealidad extrínseca, sino en el tres de su repetición. Tal es el medio, la mediación de una existencia que refluye hacia su propio ser. Porque vivimos, nos movemos y somos en el seno de la madre, lo real se justifica a sí mismo en el eterno retorno de un origen recién nacido.

El tiempo de la madre es el tiempo del nacimiento acontecido en el instante de esa memoria esencial, hacia la cual parece estar de vuelta el pensamiento contemporáneo.

University Press, 1983, p. 46.

46 S. Kierkegaard, Søren Kierkegaard's Papirer, ed. P. A. Heiberg, V. Kuhr - E. Torsting, $2^{a}$ ed., 20 vol., København: Gyldendal, 1909-1948, IV A 156.

47 J. Derrida, L'écriture et la différence, Paris: Éditions du Seuil, 1967, p. 435.

48 S. Kierkegaard, Søren Kierkegaards Samlede Varker ..., cit., III 195. 
MARÍA J. BinetTI es doctora en Filosofía e investigadora adjunta del Conicet.

Publicaciones recientes:

El idealismo de Kierkegaard, en prensa en la Universidad Iberoamericana de México.

«En el nombre de la Madre: hacia un paradigma pospatriarcal» en Revista de Filosofía, Universidad Complutense de Madrid, 37/1 (2012), pp. 137-153.

\section{Lineas de investigación:}

Sus estudios se han centrado en el pensamiento de S. Kierkegaard con especial referencia al idealismo alemán y el pensamiento francés contemporáneo.

Actualmente, su trabajo de investigación se desarrolla en el área de la filosofía feminista de la diferencia, con un proyecto sobre la reconstrucción de la «matricialidad» como categoría filosófica

Dirección Postal:

Rivadavia 1082 Luján - CP. 6700 Buenos Aires Argentina

Dirección electrónica: mjbinetti@gmail.com 